\title{
An Organisational Semiotics Approach to Multicultural Requirements Engineering: Stakeholder's Analysis of Online Shopping for Saudi Arabian Female Consumers
}

\author{
Khulood Rambo, Kecheng Liu \\ Informatics Research Centre \\ University of Reading
}

\begin{abstract}
The impact of cultural differences on systems development cannot be denied in the era of globalisation. Stakeholders' analysis is one of the most influential tasks in requirements engineering phase of the systems development life cycle. It will help us understand the sociology of the system by analysing the roles and responsibilities of each stakeholder. Furthermore; it is even more essential to implement it in multicultural settings with a wellestablished cultural knowledge base. We need to become aware of the cultural impact of an innovation on each of these stakeholders. Up to date in Saudi Arabia citizens are still reluctant to adopt online shopping. Moreover, the positive responses numbers from male consumers overshadows the female consumers' numbers. This paper will identify the stakeholders involved in the adoption of online shopping for the Saudi Arabian female market using stakeholders' identification method. Then it will analyse the cultural impact of online shopping on the stakeholders' roles and responsibilities using the valuation framing method. Both methods adopted in this paper are provided by organisational semiotics discipline. Stakeholder identification method is based on an onion model and it will identify key stakeholders, their roles, and responsibilities. While valuation framing is based on the anthropologist Hall's ten primary message systems (PMS) or as it is called the taxonomy of cultural patterns of behaviour. It aims to understand the impact of culture on stakeholders in order to detect how people involved will be affected and how they will feel about the intended innovative change.
\end{abstract}

\section{Introduction}

Multicultural systems development is no longer a phenomenon, but rather a practice resulting from conscious business decisions. Both practitioners and researchers need to become aware of the on-going cultural challenges that stakeholders face in their requirements engineering interaction [1].
Requirements engineering is a comprehension of the sociology of the system. Meaning, at this phase of systems development a modelling of the system's stakeholders and understanding of their requirements of the system are carried out [2]. Yet, involving the right stakeholders is one of the most difficult and common concerns in requirements engineering among all projects. Therefore, stakeholders' identification is the most if not the only vital process to explore, elicit, analyse, understand, specify, and test valid requirements [2].

While conflicts in requirements of different stakeholders are bound to happen, these conflicts have to be negotiated and balanced in order to develop a competitive product [1;2]. Moreover, these conflicts are even more challenging in multicultural environments; this is due to the communication and collaboration-intensive nature, as well as the inherent interaction with most other systems development processes [1]. Requirements engineering is becoming a key challenge in multicultural systems development. It is found that collaboration among stakeholder groups suffers from problems generated by differences in culture, language, attitudes towards hierarchy, and communication style. This creates a unique set of problems in the requirement engineering processes, which might lead stakeholders to tolerate ambiguity in requirements without recognising the need to collectively aim for shared understanding of requirements and its processes [1]. For this reason it is important to analyse the cultural impact of innovation on these stakeholders.

In Saudi Arabia, the majority of online consumers remain reluctant to adopt electronic commercial business to consumer transactions as online shopping applications [3;4]. It is also found that there is a perceptible significant difference between the numbers of males and females with positive responses towards adopting these applications [5;6]. Nonetheless, studies to investigate the factors that act as obstacles to Saudi female consumers' adoption of online shopping have not been found in the literature [7]. Since technology penetration in Saudi Arabia is considered as one of 
the highest among the Middle East countries, then the technical infrastructure in that territory is not an impediment $[3,4,5,6]$. But given that consumers behaviour is culture dependent, it is assumed that the majority of issues influencing Saudi citizens adoption of online shopping are merely cultural and perhaps social (socio-cultural)[6].

However, this paper aims to identify the stakeholders who take part in the issue of Saudi female adoption to online shopping application and perhaps influence the design decisions of these applications. It also aims to apply the valuation framing method to understand and analyse the cultural differences impact among stakeholders and the way they perceive the adoption of online shopping as an innovation.

The remaining part of the paper is organised as follows: section 2 provides background information about Halls ten primary messages systems (PMS) organisational semiotics, valuation farming, stakeholder identification, and the social system in Saudi Arabia. Section 3 identifies the main stakeholders who influence both the adoption and design of online shopping applications targeting Saudi female consumers. It will then implement the valuation framing method to articulate the stakeholders' cultural influence on the development of online shopping. Section 4 will discuss the main findings of the paper. Section 5 will conclude the major aspects and take home messages of the paper. And finally, section 6 will discuss the future research direction of this work.

\section{Background}

This section will provide some background information about the main topics of this paper in sequential order. The first topic is: The Saudi Arabian culture where some information about the main aspects of the culture is provided. The second topic is: stakeholders' identification where more information about the method is discussed. The third topic is: culture and Hall's ten primary messages system (PMS) where the definition of culture is discussed in addition to Hall's perspective of culture. And last but not least: the valuation framing method and how it adopts Hall's (PMS) to evaluate the cultural impact of an innovation on stakeholders.

\subsection{The Saudi Arabian Culture}

Saudi Arabia is an Islamic country. It is governed by Islamic Sharia law [7]. Sharia literally means "The Way" and refers to the body of Islamic law codified by the Quran (Holy Book) and prophetic teachings and traditions [8]. In the Saudi Arabian society both Islamic religion and Arabic traditions act as a primary force in determining the culture; i.e. social norms, patterns of behaviour, values, obligations, and practices [9;10]. Bearing in mind that Islamic law is derived from various theological schools of jurisprudence interpreting Divine Law; these scholarly interpretations vary depending on the local customs and social traditions of a specific territoriality. Meaning, we might find some practices in Saudi Arabia that are not applied in other Islamic regions. For example, some of the restrictions on Saudi female are mainly imposed by scholarly interpretations. E.g. Females are not allowed to drive in Saudi Arabia but they are allowed to do so in other Islamic countries [6;8;9].

The culture in Saudi Arabia does not permit women to mix with unrelated men. Hence, gender segregation is a general norm that touches on virtually every aspect of public and social life. It implemented in education, banking, access to public transportation and job opportunities. All these public areas and services are still strongly hold these traditional values that do not permit the mixing of the sexes. Almost all public places have areas that are restricted to women. Restaurants have special family dining rooms for women. There are shopping centres exclusively for women, and some boutiques in Saudi Arabia have a closed door with 'for Ladies only' written on it. Busses are divided into two sections to create a separate seating area for women. Even banks have women only branches $[6 ; 9 ; 10]$.

There is a strong sense in the Arabian society of what is public and what is private. In Saudi Arabia, women belong to the private world $[10 ; 11]$. In this segregated world the male-female dichotomy is linked to a public-private world where females are associated with the concept of indoors and males with the outdoors [12] (Rambo, et al., 2010). As a result, Saudi women appear in public veiled in an abaya (a thin flowing black robe that covers the entire length of the body, from head to feet); the reason Saudi Arabia became known as the land of invisible women [7].

Internet was introduced in Saudi Arabia between 1998-1999 after a long period of discussion and consultations with the Saudi authorities. It was finally agreed that a tailored version would be made available to the public. The reason for having such a filter system was that the Saudi authorities had serious concerns about the arrival of undesirable materials to the homes of the Saudi society through computer screens [12; 5].

With the recent huge expansion in public network and wireless access, government policy is changing to allow the development of new technologies while maintaining the same security and control of media use that is mandated in Saudi culture. Saudi Arabia has been linked to the internet for several years, but public access was not widely available until January 1999 [10]. Internet connectivity was launched in many universities and some government agencies in 
February 1999 [14] and made available to the public through commercial ISP [4;5].

\subsection{Stakeholder Identification}

A stakeholder in a project can be defined as someone who gains or losses something (could be functionality, revenue, status, compliance with rules, and so on) as a result of that project. In other words, a stakeholder is much more than a product's eventual "user". A stakeholder can be someone who finances the project; someone whose skill is needed to build a product, such as a network specialist or a usability expert; an organisation whose rules developers must obey, such as a tax lawyer firm or a standards institute; or an external organisation that can influence project success, such as environmental group or a competitor [1;2].

For a successful software product to be developed, it is important to identify relevant stakeholders and involve them during requirements elicitation process. As studies show that majority of software development projects fail because of lack of understanding the requirements clearly and also noninvolvement of key stakeholders [15]. They affect the development and effectiveness of enterprise technology innovation, while the mode and degree of these effects differs at each of the different stages of technology innovation process. The effects of stakeholders also have different characteristics; and the stakeholders themselves also have different benefit request and different realisation way in the technology innovation process [1;2;15].

Since Stakeholders Identification clarifies the roles and responsibilities of the actors who have a stake in a specific course of action. Stakeholders can also influence on the design decisions of the interaction solution. Some of them can have essential authorities in determining the deciding factors of information representation on the interaction solutions. It is also important to have a clear idea about the processes, procedures, and the norms governing each stakeholder's roles and responsibilities. The stakeholders' identification model implemented in this paper is presented in four spheres around the action course. Stakeholders' positions on the different spheres are determined by the impact of their roles and responsibilities on the course of action. Some are involved directly such as the actor and principal while others are detached from the action course although they are quite influential throughout the process of the course of action from the beginning to the end [16;17;1].

In this paper we model stakeholders based on their roles and responsibility in the project using an onion diagram. The deceptively simple looking model actually conceals a wealth of project information, both structurally and metaphorically. First, it presents a view of the project that centres on what we're building. We call this the action course, the equipment, or the product to distinguish it from our system, which includes generic slots for the people who operate and maintain the equipment and deliver its results, as well as any standard rules or procedures they use to operate it.

\subsection{Culture and Hall's Primary Messages Systems}

The word culture (the Latin called it 'colo,-ere', 'to cultivate', 'to inhabit' or 'to honour') has been defined and used in many ways throughout different contexts [18]. According to Hall, culture is not one thing but a complex series of activities interrelated in many ways, activities with origins deeply buried in the past when there were no cultures or humans. The development of language and technology, an interrelated pair, made possible the storing of knowledge [19]. Nonetheless, it is found in the literature more than 156 different definitions for culture can be identified [18]. One of the most popular definitions of culture in the field of anthropology is suggested by the British anthropologist Edward Taylor in the nineteenth century. Taylor defines culture as "the complex whole which includes knowledge, belief, art, morals, law, custom, and any other capabilities and habits acquired by man as a member of society". A more recent definition of culture by Downs is "a mental map which guides us in our relations to our surroundings and to other people" [20].

One of the issues that concerned the anthropologist Hall was how one culture differs from another and how one can communicate this difference in general terms [19]. He defined ten separate kinds of human activity which he labelled primary message systems (PMS). One can start the study of culture with any one of the ten and eventually come out with a complete picture. The primary message systems (PMS) are:

Interaction To interact with the environment is to be alive and to fail to do so is to be dead, when two or more people or things communicate with or react to each other, e.g. language, vocal inflections means of communication, posture, gesture, and so on $[19,21]$.

Association All living things arrange their lives in some sort of recognisable pattern of association. The concern here is about the various ways in which societies and their components are organised or structured, e.g. community, class, caste, roles, organisation, teams, hierarchy, and so on [19,21].

Subsistence is included in everything from individual food habits to the economy of a country, e.g. physical livelihood, eating, excretion and (indirectly) income working for a living [19,21]. 
Bisexuality (classification) Behaviour that is exhibited by male in one culture may be classed as feminine in another. All cultures differentiate between men and women, and usually when a given behaviour pattern becomes associated with one sex it will be dropped by the other, e.g. differentiation of sexes, marriage, family $[19,21]$.

Territoriality It is a technical term used to describe the talking possession, use and defence of a territory on the part of living organisms. Salesmen and distributors have their own territories which they will defend like any other living organism. The symbolism of the phrase "to move in on someone" is completely accurate and appropriate, e.g. division of space, where things go, where to do things, ownership [19,21].

Temporality such practices as age-grading (in a society according to rather rigid age groups) combines both time and association. It means long lead times, repetitive work because of iterations, many face to face meetings, i.e. division of time, when to do things, sequence duration, cycles [19,21].

Learning and Acquisition people in different cultures learn to learn differently and go about the process of acquiring culture in their own way. Learning to learn differently is something that has to be faced by multicultural stakeholders who have stake in the same project. It seems inconceivable to the average person brought up in one culture that something as basic as this could be done differently from the way they themselves were taught. The fact is, however, once people have learned to learn in a given way, it is extremely hard for them to learn in any other way. This is because the process of learning they have acquired a long set of tacit conditions and assumptions in which learning is imbedded. The rest of culture reflects the way one learns, since culture is "learned and shared behaviour". Learning, then, is one of the basic activities of life. However, these differences represent one of the barriers that have to be overcome each time two people raised in different cultures interact over any but the shortest period of time, i.e. education, training, rearing, what gets taught or learned [19,21].

Play people laugh and tell jokes, knowing the humour of people from different cultures, will give you a wealth of information about that specific culture. Many people around the world have what are known as" joking relationships", also in some cultures, there is a category of relationship known as the "play mate" e.g. recreation, fun, games, art, sport, what is amusing [19,21].

Defence (Protection) Human beings use defensive techniques in many matters in their lives such as warfare, territory, religion, medicine (against diseases), and law enforcement (against criminals). They feel they must cope within destructive forces within their own persons. The main point which should be kept in mind is about the way different cultures tend to treat religion. In the Middle East, Islam plays a more pervasive role than Christianity does today in Europe. People in the western world have difficulty grasping the extent to which religion pass through all aspects of life in the Arab world. The content of religion, its organisation, and the manner in which it is integrated with the rest of life varies greatly from culture to culture, e.g. protection against elements, other groups, disease and the supernatural [19,21].

Exploitation human beings developed extensions of practically everything we used to do with our bodies. All manmade material things can be treated as extensions of what was once done with the body or same specialised part of the body [22]. A transportation vehicle for example is an extension of what we use to do with our feet, i.e. tools, technology, systems, materials and their uses, skills $[19,21]$.

\subsection{Valuation Framing}

Valuation framing is another method proposed by MEASUR (methods for eliciting, analysing, and specifying user requirements) [21]. These techniques deals with matching the system design effort to the social and economic infrastructure, matching the communications subsystems to the informal exchange of information, and matching the control subsystem to the prevailing ethical practices.

Valuation framing takes Hall's ten categories of cultural norms, slightly modifies them and applies them quite differently to gauging the impact of an innovation by treating the general culture and the subcultures of the stakeholders as though they were musical instruments made of resonant networks of strings that the innovation strikes to produce the reverberations of the stakeholders' reactions that the IS designer must listen to. That's a no trivial, quite novel and a useful extension of Hall's work [21].

The valuation will be applied taken into account the interest of all stakeholders. The total system will be the object of valuation. The stakeholder will be accustomed to having, in his familiar cultural setting, a range of available behaviour patterns. These cultural patterns are divided into the ten areas 
discussed above and subsequently the analyst asks, hypothesizes or predicts how the proposed innovation will affect the stakeholders that were identified[16,17,21,23].

There will be impacts on how people communicate, how they associate, their subsistence or economic position, differential effects for the two sexes, their use of time (temporality) and space(territoriality), how they learn to use the new system, how it affects their creative or recreational behaviour, their vulnerability of power (protection), and their tools and skills. The technique of valuation framing assesses the cultural impact of technological innovation on all the stakeholders. Hall's ten criteria are the criteria for a full assessment of gains and losses of each stakeholder in relation to the innovation or change in the social system $[17,23]$.

\section{Stakeholders Analysis}

In this section an implementation of the two methods discussed above will be carried out. The first method is stakeholder identification (3.1) to identify stakeholders involved in online shopping adoption and design for online Saudi female consumers. The second method is valuation framing (3.2) to analyse the cultural impact of adopting online shopping on each of the stakeholders.

\subsection{Stakeholders Identification}

As mentioned above; collaboration among multicultural stakeholder groups suffers from problems generated by differences in culture, attitude towards hierarchy as in the perceived relationships between superiors and subordinates, and communication style. This will influence how some stakeholders are open to decline new functionality requests or tolerate ambiguity in requirements without recognising the need to collectively aim for shared understanding of requirements or requirements processes [1,2].
Before applying the stakeholders' identification method, we need to define the action course. In this paper, the online shopping adoption by Saudi female consumer is being considered the action course. Stakeholders Identification is important in defining the key people involved in the facilitation of online shopping to Saudi females. Figure 1. Shows the stakeholder Identification model implemented in this paper [24].

The first sphere - Contribution Interdependency is the nearest sphere to the action course which is the adoption of online shopping applications by female consumers. This sphere will contain the main stakeholders who have direct contribution to the action course.

stakeholders are identified in this sphere are: (1) Principals: Online retailers in Saudi Arabia are perceived to be the agents who envisioned the value of online shopping and put the other stakeholders on connection and contact. (2) Actors: Online female consumers in Saudi Arabia are the actors in this context [24].

The second sphere - Source Interdependency is one sphere distant from the action course so it contains stakeholders who are still involved in the adoption process of female consumers to online shopping. Stakeholders identified in this sphere are: (1) Providers: Internet Service Providers supply actors with the desired equipment they work with. In this context they are the online shopping retailers and they are responsible for providing all the necessary conditions to complete the online shopping process from start to end, starting from the accessibility, usability, and appropriateness of the online shopping websites targeting female consumers in Saudi Arabia to the management of both delivery of the item to the consumer and issues customer services such as returns, refunds, and exchange products. (2) Clients:

Figure 1 should be placed in this box 
In this context the shipment and delivery services are the beneficiaries who are in charge once the purchased product(s) are dispatched from the providers to deliver it to consumers. Also they are responsible from picking the product(s) from consumers for return, exchange, and refund purposes [24].

The third sphere - Market Interdependency as stakeholders in this sphere have specific indirect collaborative and competitive behaviours towards the action course compared to the actors and principles located in the first sphere. The stakeholders in this sphere are in conflict with the system over dividing up resources and markets. Stakeholders identified in this sphere are: (1) Collaborators: In the context of this paper the collaborators are the bank and payment services during the completion of the online purchasing process. (2) Competitors: High street retailers are the competitors of online shopping as they share the target market (Saudi female consumers) and their resources [24].

The fourth sphere - Community Interdependency is the outermost sphere from the action course which means that stakeholders identified in this sphere have no direct influence on the action course. Nonetheless, stakeholders identified in this course have influence on the stakeholders identified in the contribution sphere. Stakeholders in this sphere are: (1) Legislators: The Saudi ministry of commerce and industry are considered the legislators in the case of online shopping.(2) Bystanders: male guardian who has the authority to permit the actor (Female) to proceed with the online shopping process or to stop her from doing so. The male guardian permission is essential to get the hardware and software ready to use. Such as providing Internet access and finances to complete the internet subscription as well as proceed with the online payment. Regardless if the female consumer is financially dependent (Student or house wife) or financially independent (employed) in both cases the mail guardian authorisation to the process can be vital to the adoption such applications. Table 1 summarise the identified stakeholders and their roles and responsibilities [24].

Table 1. Roles and responsibilities of stakeholders

\begin{tabular}{|l|l|l|l|}
\hline \multirow{2}{*}{$\begin{array}{c}\text { Online } \\
\text { female } \\
\begin{array}{c}\text { consum } \\
\text { er }\end{array}\end{array}$} & \multicolumn{3}{|c|}{ Stakeholders Roles and Responsibilities } \\
\cline { 2 - 4 } & Stakeholder & Role & Responsibility \\
\hline $\begin{array}{l}\text { Contrib } \\
\text { ution } \\
\text { sphere }\end{array}$ & $\begin{array}{l}\text { online } \\
\text { female } \\
\text { consumer }\end{array}$ & Actor & $\begin{array}{l}\text { To take the online } \\
\text { purchasing action to } \\
\text { receive the desired }\end{array}$ \\
\hline
\end{tabular}

\begin{tabular}{|c|c|c|c|}
\hline \multirow{2}{*}{$\begin{array}{c}\text { Online } \\
\text { female } \\
\text { consum } \\
\text { er }\end{array}$} & \multicolumn{3}{|c|}{ Stakeholders Roles and Responsibilities } \\
\hline & Stakeholder & Role & Responsibility \\
\hline & & & good \\
\hline & $\begin{array}{l}\text { Internet } \\
\text { Service } \\
\text { Providers }\end{array}$ & Principal & $\begin{array}{l}\text { To envision values of } \\
\text { online shopping and } \\
\text { connect all } \\
\text { stakeholders together }\end{array}$ \\
\hline \multirow{2}{*}{$\begin{array}{l}\text { Source } \\
\text { sphere }\end{array}$} & $\begin{array}{l}\text { Shipment } \\
\text { and } \\
\text { Delivery } \\
\text { Companies }\end{array}$ & Client & $\begin{array}{l}\text { To gain benefit from } \\
\text { performing online } \\
\text { shopping and lose } \\
\text { benefits when online } \\
\text { shopping is not used }\end{array}$ \\
\hline & $\begin{array}{l}\text { Online } \\
\text { Retailers } \\
\text { Web } \\
\text { designers }\end{array}$ & Provider & $\begin{array}{l}\text { To facilitate necessary } \\
\text { conditions to perform } \\
\text { online shopping }\end{array}$ \\
\hline \multirow[b]{2}{*}{$\begin{array}{l}\text { Market } \\
\text { sphere }\end{array}$} & $\begin{array}{l}\text { Electronic } \\
\text { finanical } \\
\text { payment } \\
\text { institutions }\end{array}$ & $\begin{array}{l}\text { Collabora } \\
\text { tor }\end{array}$ & $\begin{array}{l}\text { To have some } \\
\text { beneficial agreements } \\
\text { with principals and } \\
\text { providers } \\
\text { performing from } \\
\text { shopping }\end{array}$ \\
\hline & $\begin{array}{l}\text { High street } \\
\text { retailers }\end{array}$ & $\begin{array}{l}\text { Competit } \\
\text { or }\end{array}$ & $\begin{array}{l}\text { To share target market } \\
\text { and resources with } \\
\text { principals which leads } \\
\text { sometimes to benefits } \\
\text { collision. Only if High } \\
\text { Street retailers are not } \\
\text { available in online } \\
\text { market. }\end{array}$ \\
\hline \multirow{2}{*}{$\begin{array}{l}\text { Commu } \\
\text { nity } \\
\text { sphere }\end{array}$} & $\begin{array}{l}\text { Male } \\
\text { Guardians }\end{array}$ & $\begin{array}{l}\text { Bystande } \\
\mathrm{r}\end{array}$ & $\begin{array}{l}\text { To have no direct } \\
\text { involvement in online } \\
\text { shopping but have a } \\
\text { direct influence on the } \\
\text { Actor's decision about } \\
\text { online shopping }\end{array}$ \\
\hline & $\begin{array}{l}\text { (KACST) } \\
\text { (CITC) } \\
\text { (Saudi } \\
\text { NIC) }\end{array}$ & $\begin{array}{l}\text { Legislato } \\
\text { rs }\end{array}$ & $\begin{array}{l}\text { To set out law, rules, } \\
\text { regulations, } \\
\text { procedures, } \\
\text { bureaucracies } \\
\text { governing } \\
\text { shopping in } \\
\text { Arabia }\end{array}$ \\
\hline
\end{tabular}

\subsection{Valuation Framing}

The valuation system method is based upon a number of interest groups or stakeholders. These will often belong to quite different subcultures with different sets of values but, moreover a proposed action course, especially an innovative one, tends to have rather different impacts on their lives, so amplifying the likely differences between the various stakeholder judgements [17].

Organisational semiotics provides two methods to conduct this kind of analysis. The two methods are complementary to one another because the former identifies the roles and responsibilities of stakeholders while the latter identifies the cultural perspectives of each stakeholder. There always must be people involved who attach values to the systems that we create, otherwise there is no point in having these systems, and normally there are several interest groups involved, the groups that attach positive or negative values to our system constitute the valuation 
framing. They include the agents who are affected by the system even when they have no primary role in creating and using it, provided that, in the long run they can affect its existence. This raise the following question in analyst's mind "who are the people whose values determine whether the system is a success or not?" [16;17].

As shown in table1 stakeholder groups come most likely from different cultures, some are locals and some are nationals while others are international ones. Stakeholders groups include:

The government (legislators), male guardians (bystanders), high street retailers (competitors), electronic payment financial institutions (collaborators), online retailers or online shops owners and the website designers (providers), shipping and delivery companies (clients), internet service providers (principals), and the Saudi female market (actors). Each of these groups will have a cultural system that governs how it will value the development of e-commerce applications targeting the Saudi female market. Different stakeholders will more likely to react differently to the proposed project. To enable a comprehensive valuation, valuation framing has been developed which is based on the ten primary message systems classification of the cultural norms [25].

The basic principle of valuation framing is as follows: The stakeholder will be accustomed to having in her/his familiar cultural setting, a range of available behaviour patterns. These cultural patterns are divided into ten areas and subsequently the analyst asks, hypothesises or predicts how the proposed innovation will affect the stakeholders that were identified above [24].

Without the checklist it is easy to overlook aspects of the situation which is analysed. Reactions, once identified can be expressed more clearly in terms of beneficial or disadvantages or even in terms which address specific feelings and attitudes.

Valuation framing can be used for making a quick scan of all stakeholders in a problem situation. This can result in an improved understanding of their cultural reverberations concerning both the existing situation and possible changes. The content of valuation framing is employed for detecting stakeholders' cultural perspectives which define certain types of action courses as a necessity or a desirable.

This section will provide examples of valuation of four different stakeholders from the four spheres identified in the stakeholder identification model. These examples will illustrate how culture can influence stakeholders' responses to the adoption and use of e-commerce applications. The first stakeholder example presented is the Saudi female consumers [25]. Table 2 explains the ten cultural taxonomies of adopting and using e-commerce applications:
Table 2: Saudi female consumers' valuation framing

\begin{tabular}{|l|l|}
\hline & Saudi Female Consumers (Actors) \\
\hline Subsistence & New frontier to enjoy shopping \\
\hline Classification & suitable for a gender-segregated society \\
\hline Territoriality & $\begin{array}{l}\text { Convenience ( worldwide shopping } \\
\text { from home) }\end{array}$ \\
\hline Temporality & $\begin{array}{l}\text { Shopping 24/7 is suitable for all } \\
\text { segments of female consumers }\end{array}$ \\
\hline Learning & $\begin{array}{l}\text { (usability issues) capable of learning } \\
\text { online shopping processes }\end{array}$ \\
\hline Play & $\begin{array}{l}\text { Depending on design, can be quite } \\
\text { amusing process }\end{array}$ \\
\hline Protection & $\begin{array}{l}\text { Security, confidentiality, privacy , and } \\
\text { safe shopping }\end{array}$ \\
\hline Exploitation & $\begin{array}{l}\text { Limited needs to visit traditional shops } \\
\text { Association }\end{array}$ \\
$\begin{array}{l}\text { associated with family and male } \\
\text { guardian's opinions }\end{array}$ \\
\hline Interaction & $\begin{array}{l}\text { Enable interaction with Arabic } \\
\text { speaking female shopping assistant(s) } \\
\text { and be aware of female social } \\
\text { interaction preferences in a gender- } \\
\text { segregated society }\end{array}$ \\
\hline
\end{tabular}

The second example of stakeholder's valuation framing exercise is e-shops or online retailers [25]. Table 3 illustrates the valuation of e-shops or online retailers:

Table 3: online retailers' valuation framing.

\begin{tabular}{|l|l|}
\hline & Online retailers \\
\hline Subsistence & $\begin{array}{l}\text { Business profitability dependent on } \\
\text { adoption of e-shopping }\end{array}$ \\
\hline Classification & $\begin{array}{l}\text { Such a target market in gender- } \\
\text { segregated society and cultural } \\
\text { constrains is a niche for successful } \\
\text { business opportunities }\end{array}$ \\
\hline Territoriality & $\begin{array}{l}\text { global e-shops enables international } \\
\text { orders }\end{array}$ \\
\hline Temporality & $\begin{array}{l}\text { Flexible timing allowing consumers to } \\
\text { shop 24/7 }\end{array}$ \\
\hline Play & $\begin{array}{l}\text { Usability issues is online retailers } \\
\text { (website designers) responsibility }\end{array}$ \\
\hline Protection & $\begin{array}{l}\text { Amusing and engaging websites is } \\
\text { online retailers (website designers) } \\
\text { responsibility, i.e. virtual fitting rooms }\end{array}$ \\
\hline $\begin{array}{l}\text { Responsible for creating trustworthy } \\
\text { websites that convey confidential, } \\
\text { secure, and private interaction }\end{array}$ \\
\hline Exploitation & $\begin{array}{l}\text { e-shops are extensions of traditional } \\
\text { shops (replace them) }\end{array}$ \\
\hline Association & $\begin{array}{l}\text { Awareness of the collective and } \\
\text { masculine cultural natures of the } \\
\text { society and influence of family on } \\
\text { individuals (female consumers) } \\
\text { decisions }\end{array}$ \\
\hline Interaction \\
$\begin{array}{l}\text { Responsible for providing websites that } \\
\text { can establish rapport with clients } \\
\text { through clear lines of trust and } \\
\text { sufficient customer relationships } \\
\text { managements }\end{array}$ \\
\hline
\end{tabular}


The third example of stakeholder's valuation framing exercise is high street shops or traditional retailers [25]. Table 4 illustrates the valuation of high street shops or traditional retailers:

Table 4: High street shops valuation framing.

\begin{tabular}{|c|c|}
\hline & High street retailers \\
\hline Subsistence & Loss of clients means loss of business \\
\hline Classification & No significant change \\
\hline Territoriality & $\begin{array}{l}\text { e-shops is more convenient than } \\
\text { visiting shops especially within } \\
\text { existing environmental and cultural } \\
\text { constrains for female consumers }\end{array}$ \\
\hline Temporality & $\begin{array}{l}\text { Restrictions of opening times and } \\
\text { closing for prayers make it easier for } \\
\text { consumers to shop online }\end{array}$ \\
\hline Learning & $\begin{array}{l}\text { Once female consumers become } \\
\text { confident in using e-shops they will } \\
\text { rarely visit h.s. shops again }\end{array}$ \\
\hline Play & $\begin{array}{l}\text { If e-shops provide sufficient } \\
\text { amusement and fun opportunities, } \\
\text { female consumers will not look for fun } \\
\text { else where }\end{array}$ \\
\hline Protection & $\begin{array}{l}\text { Once online shopping conveys safe, } \\
\text { secure, confidential, and private } \\
\text { shopping process. Female consumers } \\
\text { will no longer need to visit h.s.shops. } \\
\text { e-shopping generally endanger } \\
\text { h.s.shops }\end{array}$ \\
\hline Exploitation & $\begin{array}{l}\text { h.s.shops can open online shops as } \\
\text { extensions of their traditional shops } \\
\text { and save their clients }\end{array}$ \\
\hline Association & $\begin{array}{l}\text { Successful business in Saudi Arabia is } \\
\text { based on family bonds and social } \\
\text { relations }\end{array}$ \\
\hline Interaction & $\begin{array}{l}\text { Cultural issues of interaction in } \\
\text { h.s.shops and the fact that sales people } \\
\text { are males creates constraints in } \\
\text { shopping which can be replaced } \\
\text { sufficiently with effective e-shops } \\
\text { designs }\end{array}$ \\
\hline
\end{tabular}

The fourth example of stakeholder's valuation framing exercise is the bystander or male-guardian in this context [25]. Table 5 illustrates the valuation of male guardians:

Table 5: Male-guardian’s valuation framing.

\begin{tabular}{|l|l|}
\hline & Male-guardian \\
\hline Subsistence & $\begin{array}{l}\text { From a provider perspective; easier } \\
\text { way to spend more money }\end{array}$ \\
\hline Classification & $\begin{array}{l}\text { Satisfy gender-segregated society } \\
\text { norms }\end{array}$ \\
\hline Territoriality & $\begin{array}{l}\text { Convenience as no need to take female } \\
\text { to h.s.shops and save long waiting } \\
\text { hours }\end{array}$ \\
\hline Temporality & $\begin{array}{l}\text { Convenience as no waiting for opening } \\
\text { times is required }\end{array}$ \\
\hline Learning & $\begin{array}{l}\text { As long as it is easy and reliable for } \\
\text { female consumers to use them }\end{array}$ \\
\hline Play & $\begin{array}{l}\text { Joyful websites encourages using it. } \\
\text { keeping in mind socio-cultural norms }\end{array}$ \\
\hline
\end{tabular}

\begin{tabular}{|l|l|}
\hline & of joy within a society \\
\hline Protection & $\begin{array}{l}\text { Ensure that it does not contain any } \\
\text { inappropriate content, safe, secure, } \\
\text { confidential, and private. }\end{array}$ \\
\hline Exploitation & Limited need to visit traditional shops \\
\hline Association & $\begin{array}{l}\text { Ensure that is does not endanger family } \\
\text { bonds and enable group shopping or } \\
\text { family e-shopping facilities }\end{array}$ \\
\hline Interaction & $\begin{array}{l}\text { Ensure that it does not endanger socio- } \\
\text { cultural interaction norms within a } \\
\text { society }\end{array}$ \\
\hline
\end{tabular}

Each category in the valuation framing is treated as a separate building block, capable of being analysed in its own terms without reference to the other systems. Distinct definitions of each category have been made which will help a user of the method in constructing a proposer description of the various types of valuations.

\section{Discussion}

Requirements engineering is a key activity in the development of software systems and is concerned with the identification of the goals of the stakeholders and their elaboration into precise statements of desired services and behaviour. As studies show, majority of the software development projects fail because of lack of understanding the requirements clearly and non-involvement of key stakeholders. For the successful software product to be developed it is important to identify relevant stakeholders and involve them during requirements elicitation process [1;2].

From the stakeholders' Identification we can see the female consumers' decision of adopting online shopping applications is influenced by all other stakeholders. Starting from the legislators, online retailers who are targeting the Saudi Arabian market should become aware of the legal and social rules that enable the accessibility of their websites through the legislators' filtration to the Saudi Arabian market. Also the male guardian's perception of online shopping applications - whether he accepts the adoption or rejects it - will influence her decision. Also, the facilities provided by the financial institutions will affect the female consumers' decision (as different payment options as mentioned earlier people in Saudi Arabia are not encouraged to use credit cards due to religious reasons which indicates the need to provide other payment options by financial institutions). Also, the sufficiency of the shipment and delivery companies has a major influence on the female consumers' decision in terms of their commitment to deliver the items punctually, conditions of items...etc. The online retailers' website presentation and services can be categorised as the most important factor in the online shopping mechanism as it facilitates the environment which 
enables the female consumer to carry out the whole process of purchasing online. It provides the look, feel, and presence of shopping without the physical need to carry out the action. It is also essential to mention the role of Internet service providers and the quality of the connection they provide which makes the online shopping process possible. The high street shops are competitors of online retailers in terms of services, prices, offers, display, quality, services etc. The paper was based on existing literature and observation of the author. It provides an analysis of the people who are involved in the process of female consumers ' online shopping and the impact each one of them has on online female consumers were performed.

This paper has clarified that multicultural stakeholders will more likely have different perspectives on the features, functionality, and design decisions of a product. Also the female consumers' decision of adopting online shopping applications is influenced by stakeholders' perspectives of these products, for instance the male guardian's perception of online shopping - whether positive or negative - will more likely influence her decision. Also, the facilities provided by the financial institutions will affect the female consumers' decision (as in providing other payment options than credit cards payment since people in Saudi Arabia are not encouraged to use credit cards due to religious reasons which prohibits them to get involved in financial transactions that include interest fees. this indicates the need to provide other payment options by financial institutions). Also, the sufficiency of the shipment and delivery companies has a major influence on the female consumers' decision in terms of their commitment to deliver the items punctually, conditions of items...etc.

The online retailers' website presentation and services can be categorised as the most important factor in the online shopping mechanism as it facilitates the environment which enables the female consumer to carry out the whole process of purchasing online. It provides the look, feel, and presence of shopping without the physical need to carry out the action. It is also essential to mention the role of Internet service providers and the quality of the connection they provide which is reflected on the online shopping process sufficiency and accuracy. While the high street shops are competitors of online retailers in terms of services, prices, offers, display, quality, services etc. They will probably be influenced negatively by the introduction of such a product.

\section{Conclusion}

Finding the right stakeholders is essential to proceed with more detailed work such as modelling the context, partitioning the problem, defining the requirements and building the system according to whatever approach we are using.

The adoption of online shopping can overpass some constraints faced by female consumers in traditional shopping in Saudi Arabia. However, online shopping will only be successful if the influence of the Saudi Arabian stakeholders is taken into account. This paper analysed the stakeholders who are involved in the process of female consumers' online shopping using Organisational Semiotics social-technical approach. Stakeholders' analysis enables designers to point out some requirements that should be considered while designing online shopping applications targeting the Saudi female market.

This paper provides analysis of the cultural impact on the responses of each of the stakeholders involved in the development of online shopping applications targeting female consumers in Saudi Arabia. The information provided in this paper will enable analysts and designers to point out some requirements that should be considered while designing online shopping applications targeting the Saudi female market.

According to the theoretical analysis implemented in the paper it is found that introducing e-commerce applications to the Saudi female market is not enough for her to adopt and use these applications. This decision is made in cooperation with other stakeholders after examining the suitability if these applications to the cultural and moral beliefs of the region. Failing to consider these cultural influences in the product preparation will probably result in failing the adoption and use of these applications.

\section{Future Research Direction}

The main purpose for applying both methods (Stakeholders' identification and valuation framing) in this research is to know who the key stakeholders in this multicultural environment are. This information will help analysts to clearly highlight the main stakeholders who will contact for data collection and validation of the design solutions. In this context it is clearly that we need to bear in mind three main stakeholders: Saudi female consumers, male guardians, and the government as the legislators. Meaning, we will be mainly in touch with these three stakeholders throughout the data collection and the validation phases of this research. Future work in this regard aims to implement empirical investigations towards the influence of cultural factors on the design and adoption of ecommerce applications in Saudi Arabia. This requires modelling the social reality of e-commerce in Saudi Arabia as well as the mental models of the users (Saudi female consumers). Also identifying the socio-cultural norms and incorporating them in the 
design guidelines of these applications via implementing the Semantic Analysis Method (SAM) and Norm Analysis Method (NAM) offered by the organisational semiotics analysis discipline.

\section{References}

[1] Damian, D. Stakeholders in Global Requirements Engineering: Lessons Learned from Practice. Focus/ Stakeholders in RE. IEEE Software, 2007, Vol. IEEE Xplore, 0740-7459/07.

[2] Alexander, I and Robertson, S. Understanding Project Sociology by Modeling Stakeholders. IEEE Software/ Requirements. 2004, Vol. 21, 1.

[3] Thomas, Karen. Changing attiudes to online trading. Vol.52 Issue 32,p40-41: MEED: Middle East Economic Digest, 2008. pp. Vol.52 Issue 32,p40-41.

[4] Sait, Sadiq M, Al-Tawil, Khalid M and Hussien, Sayed Ali. E-Commerce in Saudi Arabia: Adoption and Perspectives. Dahran : AJIS, 2004. Vol. 12.

[5] Sait, Sadiq, et al. Impact of Internet Usage in Saudi Arabia: A Social Perspective. s.l.: International Journal of Information Technology and Web Engineering, 2007. pp. 81-115.

[6] Rambo, K, Liu, K and Nakata, K. The SocioCultural Factors Influencing Online Female Consumers in Saudi Arabia. Vancouver, IEEE International Conference on Social Computing : IEEE Computer Society, 2009. Vol. International Conference on Computational Science and Engineering.

[7] Ahmed, Q. 2008. In The Land of Invisible Women: A female Doctor's Journey in the Saudi Kingdom. Naperville, Illinois : Sourcebooks, 2008.

[8] Esposito, J and Mogahed, D. Who Speakes for Islam? what a billion muslims really think. New York : Gallup Press, 2007.

[9] Almunajjed, M. Women In Saudi Arabia Today. London : Palgrave, 1997. 0333638123.

[15] The internet gains acceptance in the Persian gulf. Goodman, S. 19-24, s.l. : Communication of the ACM, 1998, Vol. 41.

[10] Al-Saggaf, Y. The Effect of Online Community on Offline Community in Saudi Arabia. Wagga Wagga, School of Information Studies, Charles Sturt University: EJISDC (Electronic Journal on Information Systems in Developing Countries), 2004. Vol. 16. 1-16.
[8] Hippel, V. The dominent role of users in the scientific instrument innovation process. s.l.: REsearch Policy, 1976.

[9] The Challenge of fifth generation $R \& D$. Rogers, D. 1996. Research Technolgoy Manegment. Vols. 39, 33-41.

[10] The Internet in Saudi Arabia. Al-Tawil, K. s.l. : Telecommunications Policy/ Pergamon/ Elsevier Science Ltd., 2001.

[11] Lipsky, G. 1952. Saudi Arabia. Its people, its society, its culture. s.l. : HRAF Press, 1952.

[12] Rambo, K and Liu, K. 2010. A Semiotic Diagnosis of Culture-Sensitive Virtual E-Commerce Design: With Reference to Female Consumers in Saudi Arabia. [book auth.] B Ciaramitaro. Virtual Worlds and E-Commerce. s.l.: IGI Global (in process of getting published), 2010.

[13] Abou-Elfadl, Khaled. The Great Theft: Wrestling Islam from the Extremist. San Francisco: Harper San Fransisco, 2005.

[14] The internet gains acceptance in the Persian gulf. Goodman, S. 19-24, s.l. : Communication of the ACM, 1998, Vol. 41.

[15] The Influence of Stakeholders on Technology Innovation: A Case Study from China. Ya, S and Rui, T. s.l. : IEEE Computer Society, 2006. IEEE International Conference on Management of Innovation and Technology. Vols. 1, Pages 295 299.

[16] Liu, K. Semiotics In Information Systems Engineering. Cambridge: Cambridge University Press, 2000. 0-521-59335-2.

[17] Kolkman, M. Problem Articulation Methodology. s.l.: PhD Thesis, Enschede, 1993. 9090059725.

[18] Cultural Computing and the Self Concept: Towards Unconscious Metamorphosis. Kooijmans, Tijn and Rauterberg, Mathias. 2007. Amsterdam : IFIP , 2007. IFIP International Federation for Information Processing.

[19] Hall, Edward T. 1959,1981. The Silent Language. New York : Doubleday, 1959,1981.

[20] Ferraro, Gary. 2001. Cultural Anthropology: An Applied Perspective. s.l.: Wadsworth, thomson learning, 2001. 0-594-55626-4. 
[21] Analysing the Cultural Impact of a System. Stamper, R. 1988. 107-122, International Journal of Information Management: Butterworth, 1988, Vol. 8. 0268-4012/88/02.

[22] McLauhan, M, Fiore, Q and Agel, J. 2001. The Medium is the Massage. s.l. : Gingko Press, 2001. 978-1584230700.

[23] Tan, S. 2006. A semiotic Approach to Enterprise Infrastructure Modelling - The Problem Articulation Method for Analysis and Applications. School of Systems Engineering, University of Reading : $\mathrm{PhD}$ Thesis, 2006.

[24] Rambo, K and Liu, K. (2010). Articulating Stakeholders Perspectives of Culture-Sensitive Ecommerce Design Targeting Female Consumers in Saudi Arabia, in Proceedings of International Conference on Information Society- IEEE UK/RI Computer Society. London, UK.

[25] Rambo, K and Liu, K. (2010). Cultures, Roles, and Responsibilities of Stakeholders in Multicultural Requirements Engineering: Designing e-commerce for Female Market in Saudi Arabia, in Proceedings of International Conference on Informatics and Semiotics in Organisations - INSTICC. Reading, UK. 